This item was submitted to Loughborough's Research Repository by the author.

Items in Figshare are protected by copyright, with all rights reserved, unless otherwise indicated.

\title{
New tools for managing daylight exposure of works of art: case study of Hambletonian, Mount Stewart, Northern Ireland
}

PLEASE CITE THE PUBLISHED VERSION

http://dx.doi.org/10.1080/19455224.2016.1214610

\section{PUBLISHER}

Taylor and Francis / @ The Institute of Conservation

\section{VERSION}

AM (Accepted Manuscript)

\section{PUBLISHER STATEMENT}

This work is made available according to the conditions of the Creative Commons Attribution-NonCommercialNoDerivatives 4.0 International (CC BY-NC-ND 4.0) licence. Full details of this licence are available at: https://creativecommons.org/licenses/by-nc-nd/4.0/

\section{LICENCE}

CC BY-NC-ND 4.0

\section{REPOSITORY RECORD}

Blades, Nigel, Katy Lithgow, Stephen Cannon-Brookes, and John Mardaljevic. 2019. "New Tools for Managing Daylight Exposure of Works of Art: Case Study of Hambletonian, Mount Stewart, Northern Ireland". figshare. https://hdl.handle.net/2134/22411. 


\title{
NEW TOOLS FOR MANAGING DAYLIGHT EXPOSURE OF WORKS OF ART: CASE STUDY OF HAMBLETONIAN, MOUNT STEWART, NORTHERN IRELAND
}

Nigel Blades, Katy Lithgow, Stephen Cannon-Brookes and John Mardaljevic

Keywords: Daylight Fading Painting Mesh Modelling Dome

\begin{abstract}
This paper describes a project to reduce the excessive daylight exposure of an oil painting, Hambletonian, Rubbing Down, displayed at Mount Stewart, Northern Ireland. Climate-based daylight modelling (CBDM) was used to understand the light exposure of Hambletonian and to assess the impact of control measures on the annual light exposure and viewing condition of the painting in the winter months. The computer model was used in conjunction with measured lux data to establish the base case light exposure and the effect of the control measures. Light control was implemented through the use of darker paint finishes on the walls and ceiling, which reduced the amount of reflected light reaching Hambletonian; and the addition of a mesh screen to the outside of the glazed dome above the painting. These interventions were cost-effective and straightforward to implement and manage. CBDM suggests the interventions reduced Hambletonian's annual daylight exposure from $3.5 \mathrm{mlxhr}$ to $0.63 \mathrm{mlxhr}$.
\end{abstract}

\section{Introduction}

National Trust historic house interiors rely principally on daylight for illumination of objects and artworks on display. Daylight adds interest and variety to the display of collections but is more difficult to manage for conservation than electric lighting. Spaces with skylights and domes can be particularly challenging as they often receive high levels of daylight, including direct sun. Traditional light control measures such as blinds may be impossible to introduce in this type of space and other solutions must be sought.

This paper describes an applied research project to protect one of the most important paintings in the National Trust from excessive daylight exposure. Hambletonian Rubbing Down hangs below the roof lantern on the Main Staircase at Mount Stewart, Northern Ireland. The research employed Climate Based Daylight Modelling (CBDM), in one of the first applications to a UK heritage building, to 
understand the fall of daylight on Hambletonian, its annual light exposure and the effect of proposed light control measures. The use of CBDM with measured light data to develop a practical and effective light control solution are described. The light control measures were implemented as part of a larger National Trust conservation and re-presentation project at Mount Stewart

\section{Background}

1 The painting

Hambletonian, Rubbing Down by George Stubbs RA (1724-1806) is celebrated not only for its portrayal of one of the greatest racehorses of the late 18th century, but also for its powerful yet restrained expression of the impact of victory (Fig. 1). Hambletonian was commissioned in $1799-1800$ by Sir Henry Vane-Tempest (17711813) to mark his horse's victory over Mr Joseph Cookson's Diamond at Newmarket on 25 March 1799. ${ }^{1}$ The event attracted national attention and prodigious betting with Sir Henry winning 3,000 guineas. ${ }^{2}$ After the hard-living baronet's early death in 1813, the painting passed to his daughter, Frances Anne, Marchioness of Londonderry and it hung at Wynyard Park, near Durham, for nearly 150 years, although its exact location is uncertain. When the house became a school during the Second World War its contents went to other family houses and the Library at Londonderry House, London, received Hambletonian, Rubbing Down. When Londonderry House was sold in 1962, the painting was sent to the family's remaining seat, Mount Stewart in Northern Ireland, where it has been displayed on the main staircase ever since.

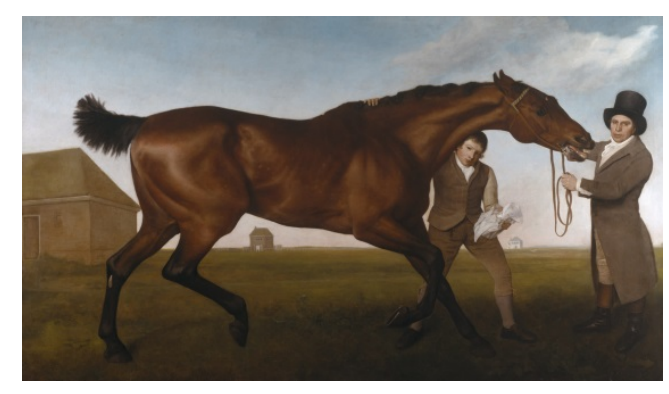

Fig. 1. Hambletonian, Rubbing Down NT inventory no 1220985, by George Stubbs RA (1724-1806) CNational Trust 
Mount Stewart was bought in 1744 by Alexander Stewart (1697-1781), an Irish landowner and MP and founder of the Londonderry family fortunes. The original timber house beside Strangford Lough known as Mount Pleasant was remodelled in 1804 under the supervision of Alexander's son Robert Stewart, 1st Marquess of Londonderry. Influenced by the designs of George Dance the Younger, an 'imperial' staircase with divided symmetrical flights was built, lit dramatically by segmental pendentive domes (Fig. 2), a device adopted by Sir John Soane, Dance's pupil. Hambletonian's position here has been generally considered most suited to the painting's enormous physical $(2.1 \mathrm{~m} \times 3.7 \mathrm{~m})$ and artistic presence. ${ }^{3}$

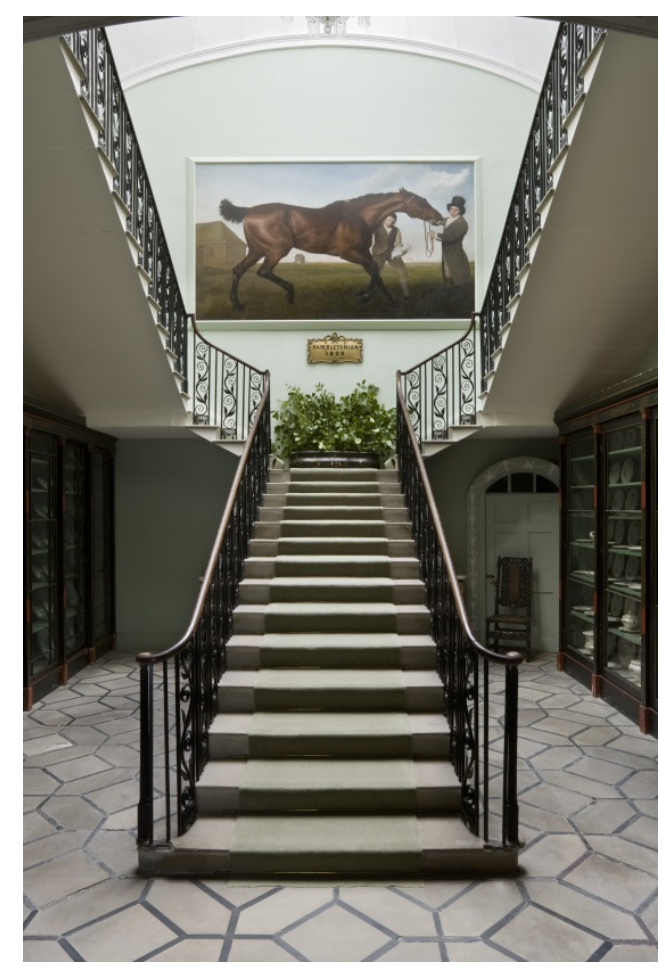

Fig. 2. The divided main staircase at Mount Stewart with Hambletonian, as displayed until the end of 2013. CNational Trust Images/John Hammond.

\section{Conservation concern}

Mount Stewart was handed to the National Trust in 1977 by Lady Mairi Bury, youngest daughter of Edith, Lady Londonderry (1878-1959), the great political hostess and wife of the $3^{\text {rd }}$ Marquess, whose favourite residence Mount Stewart became (the gardens having been taken over in 1957). Soon after Mount Stewart 
came to the National Trust, staff began to worry about the impact of uncontrolled top lighting on Hambletonian. Various light-control options were considered, including a fibreglass dome (as used at Saltram, Plymouth), mechanical louvre blinds (as used at Upton, near Banbury), and ingeniously draped sun curtains. It was decided to install diffusive frosted glazing incorporating an ultraviolet (UV) filter in the lantern. A mechanical louvre blind system was installed externally in 1985. This mechanism failed soon after installation, fixing the louvres in place in their closed position. Whilst effective in excluding light the resulting striped effect was unsatisfactory aesthetically, as well as preventing the play of fluctuating daylight considered essential to animate the architecture, so the louvres were removed in $2005 .{ }^{4}$ From that date until the present project there was no other light control for Hambletonian. From 2006 electronic dataloggers and blue wool dosimeters were used to measure Hambletonian's light exposure, in order to inform the design of appropriate light control.

\section{Condition}

Concern over small areas of cupped paint, a very discoloured varnish, and fragile tacking margins, led to Hambletonian's conservation by the Hamilton Kerr Institute (lan McClure and Rupert Featherstone) in 1981-1983, prior to its loan to the 1984 George Stubbs 1724-1806 exhibition at the Tate Gallery. ${ }^{5}$ The catalogue includes a summary of the conservation and technical examination so only details relating to light sensitivity, such as faded pigments, are discussed in the following section. ${ }^{6}$

\section{Technique and light sensitivity}

Stubbs experimented with wax along with many other artists in the eighteenth and nineteenth centuries, in search of the perfect - durable, translucent - paint medium. Analysis revealed the presence of beeswax and pine resin in addition to drying oil, especially in the landscape, whilst other areas (such as the sky) were painted mostly in oil. This is typical of the change Stubbs made in his technique in the 1780 s from primarily wax and resin to primarily oil, wax and resin. ${ }^{7}$ The presence of wax raised concerns over heating from sunlight (the solubility of wax also makes the painting very vulnerable to damage by solvent cleaning). Examination revealed that the 
painting had previously been varnished five times, and that the underlying varnish layers had deteriorated with fissuring and discolouration probably caused by high levels of light exposure.

Photo-sensitive pigments were also found. A possible red lake outlined tiles in the rubbing down house to the left of the painting, which had faded to the point that the lines were visible only under ultraviolet illumination. Prussian Blue, known to fade to grey in sunlight particularly when mixed with white, was found mixed with lead white and calcium carbonate in the sky (this instability appears to be exacerbated by variation in manufacturing techniques). ${ }^{8}$ Orpiment, which can photo-oxidise to white arsenic trioxide was mixed with Prussian Blue to create the greens of the landscape, along with yellow ochre, Patent yellow, and possibly Naples yellow. ${ }^{9}$ In other studies orpiment has been found to darken under accelerated light ageing, possibly as a result of organic media or consolidants. ${ }^{10}$

National Trust lighting policy is based on the annual light exposure considered appropriate for moderately or highly light sensitive materials, of 600,000 lux hours (0.6 mlxhr) and 150,000 lux hours (0.15 mlxhr) a year respectively. ${ }^{11}$ Oil paintings are normally considered moderately light sensitive, although the pigments involved could be considered to justify the classification of Hambletonian as highly light sensitive. It could be argued however, that all the light damage that could affect the highly light sensitive pigments has already occurred. Further technical analysis would be needed to establish whether orpiment or red lake survive unaltered below the paint layer surface.

Hambletonian has been displayed on the main stairs at Mount Stewart since the early 1960s. From the Second World War until 1962 Hambletonian was hung in a side lit location in the Library at Londonderry House, London (Fig. 3), where it is unlikely to have received the annual megalux exposures experienced at Mount Stewart. The lighting regime at Wynyard Park, where the painting spent the previous 150 years, is unknown. Some light damage would undoubtedly have been caused in these historic locations, but we can only speculate as to how much light damage occurred prior to display at Mount Stewart.

From the measurements begun after 2005, it was clear that Hambletonian's daylight exposure in the absence of light control, other than the UV-filtered diffusive frosted glazing, was far in excess of the 600,000 luxhours recommendation. This 
observation, coupled with knowledge of Hambletonian's significance and vulnerability of the sky pigments, led to the research described in this paper.

The research sought, through a combination of measured data analysis and climate-based daylight modelling (CBDM), to understand the current daylight exposure of the painting; and to test and quantify the impact of interventions to reduce light exposure.

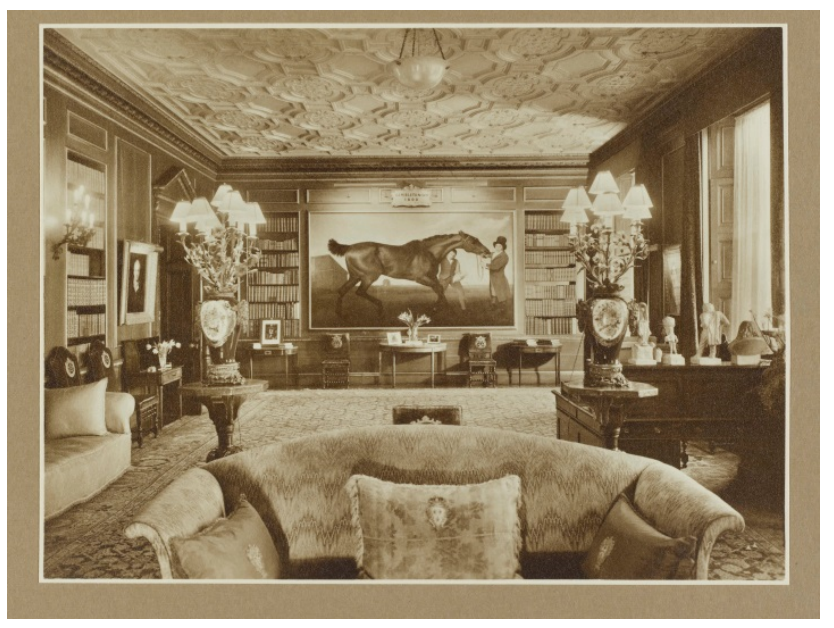

Fig. 3.Hambletonian displayed in the Library of Londonderry House, prior to its installation at Mount Stewart. (C) Country Life.

\section{Analysis of existing lux and cumulative exposure measurements and daylight modelling}

\section{Measurement of light exposure}

Following the removal of the external louvres in 2005, a lux data logger, radiotelemetric lux and UV sensor, and blue wool light dosimeters were placed adjacent to the painting (location 2 in Fig. 4). The assessment of the colour shift of blue wool No. 3 dosimeters by Trust staff yielded a wide range of light exposure values. As only one sample had been exposed for a complete year, normalisation was attempted based on the dates for the samples' exposure. This was undertaken using averaged global horizontal (i.e. sky and sun) illuminance data divided by month from the International Weather for Energy Calculations (IWEC) Test Reference Year weather file compiled from measurements taken at Aldergrove, Belfast. Global horizontal illuminance is the total light (in lux) from the sun (if present) 
and an unobstructed sky incident on a horizontal surface. Diffuse horizontal illuminance is that which is due only to the unobstructed sky. The resulting annual exposure values for the blue wool dosimeters varied between $1.6 \mathrm{mlxhr}$ and $7 \mathrm{mlxhr}$, a degree of variance substantially greater than expected. It was not possible to review in detail the Hambletonian blue wool monitoring procedures and exact locations from up to ten years previously. Since this variance does not accord with experience of using blue wool dosimeters elsewhere in the Trust, it was concluded that the data were not reliable and would have to be set aside.

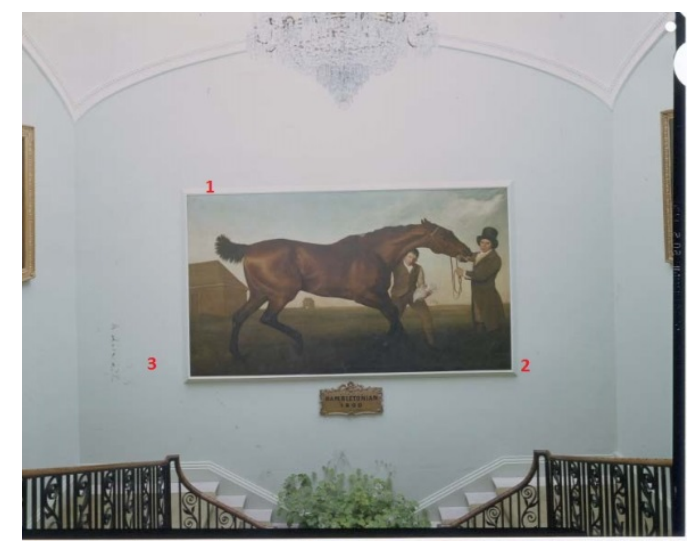

Fig. 4. Hambletonian as displayed in 2011 without light control and with the original flush-mounted wall frame. Radiotelemetric lux sensor and lux data logger were in location 1, blue wool dosimeters location 2. After redisplay in early 2015 the radiolotelemetric sensor was relocated to location 3. CNational Trust.

Exposure recorded by electronic data loggers (location 1, Fig 4.) also proved to be partial and initially only two solstice to solstice periods could be used. Both required limited normalisation to fill in missing data, once again using averaged global horizontal illuminance data. This yielded more consistent results with the top left of the painting receiving annual exposure of $4.6 \mathrm{mlxhr}$ (datalogger 2006) and $4.1 \mathrm{mlxhr}$ (telemetric sensor, 2011) and $3.3 \mathrm{mlxhr}$ (telemetric sensor, 2012-13). The datalogger used in 2006 was tilted slightly back and was expected to record a higher exposure. Its results were therefore set aside. It was decided to use the average of the 2011 (4.1 mlxhr) and 2012-13 (3.3 mlxhr) total annual light exposure $=3.7 \mathrm{mlxhr}$ as a base value for Hambletonian's light exposure prior to the introduction or modelling of additional light control measures. The radiotelemetric lux sensor placed on top of Hambletonian's frame (position 1) also recorded UV. For the summer monitoring period May-August 2012 the maximum daily UV level, recorded at hourly intervals, averaged $80 \mu \mathrm{W} / \mathrm{lumen}$, indicating that UV filtration was reasonably effective. 
2 Computer simulation of daylighting in the Main Staircase

Accurate simulation of daylight performance in interiors is reliant both on the quality of representation in the physical building model and the data / software employed to calculate light distribution. A 3D model of the Staircase area was created using data from a laser scanner survey undertaken by John Meneely at Queen's University Belfast. This provided a precise set of dimensions of internal building surfaces which would have been difficult to capture without erecting scaffolding. In situ assessments were carried out to record the reflectivity of surfaces using the colour cards supplied with Lighting Guide 11 published by the Society of Light and Light and the National Physical Laboratory (NPL). ${ }^{12}$ The transmission of the existing glazing was tested using an illuminance meter, where a section of glass overhangs the perimeter of the oculus. The technique used was to measure the percentage reduction between the level incident on the glass and directly under the same spot. The near-Lambertian (diffusing) performance of the diffusive frosted glazing was confirmed by Trust staff at Mount Stewart who have observed no significant highlighting or brightness patches on the walls of the Staircase during periods of sunlight. The spectral power distribution (SPD) of daylight varies considerably according to the climatic conditions (sun, sky, cloud) and time of day. Additionally, the SPD of daylight entering a space will be modified by the transmissive properties of the glazing and the reflective properties of the walls, floors, ceiling, furnishings, etc. The Commission Internationale d'Eclairage (CIE) define D65 as a standard daylight illuminant, but for the reasons described above, there is no standard for daylight illumination inside a building. However, for a daylight SPD to be perceived as non-neutral (i.e. with a distinct hue), it is generally case that the majority of the glazing would need to be tinted.$^{13}$ The SPD of daylight in the Stone Staircase was not monitored, however no noticeable hue in the illumination has ever been reported, nor noticed during visits by any of the authors.

Climate-based daylight modelling (CBDM) is the prediction of any luminous quantity (illuminance and/or luminance) using realistic sun and sky conditions derived from standardised climate data. The 4-Component CBDM approach was developed by co-author John Mardaljevic and is used in-house at Loughborough University for research, teaching and practical application to 'live' projects worldwide. The authors 
believe that this is the most rigorous approach to the prediction of daylight performance and the most likely to provide an accurate basis for predicting proposed changes to the lighting conditions of Hambletonian. ${ }^{14}$

The initial stage of the simulation research was to model existing lighting conditions and annual exposure. CBDM evaluations are usually carried out for a full year at time-steps of an hour or less in order to capture the daily and seasonal dynamics of natural daylight. The principal sources of base data for CBDM are standard meteorological files (used also for the normalisation described above). These files contain hourly values for various irradiation and illumination quantities, from which it is possible to derive hourly-varying sky and sun conditions for use in lighting simulations, i.e. where each unique sun/sky combination "illuminates" the virtual building model. The resulting predictions for fluctuating daylight can be aggregated to give an annual daylight exposure value in lux hours per year. Alternatively, if only cumulative annual daylight exposure is required, it can be simulated directly from a sun and sky description that contains the aggregated contribution of all the unique hourly sky and sun configurations synthesised from the climate data. Both methods were used for this research.

The Radiance lighting simulation system is used as the 'engine' for the CBDM approach employed in this study. ${ }^{15}$ What is probably still considered the definitive validation study for any daylight prediction method (physical model, analytical or simulation) was carried out in the mid-1990s using data collected by the Building Research Establishment (BRE) as part of the International Daylight Measurement Programme - the data are referred to as the BRE-IDMP validation dataset. ${ }^{16}$ That study showed that illuminances predicted using the Radiance system for a point in time calculation (for a particular sun and sky configuration) could be within $\pm 10 \%$ of measured values, and, as such, within the accuracy limits of the measuring instruments themselves. This quite remarkable degree of precision needs to be judged alongside the high level of inaccuracies (often in excess of $100 \%$ ) that were determined to be fairly typical for physical modelling. ${ }^{17}$ For CBDM, a prediction for all the daylight hours of the year is required, that is, the hour-by-hour illuminance values resulting from all of the approximately 4380 sun and sky conditions that are derived from a standardised climate dataset for a particular locale. A brute-force approach would require the solving of 4380 computationally expensive daylight simulations, which would require considerable computer time. However, the 4-Component 
method uses a refined version of the daylight coefficient approach, whereby any number of arbitrary sun and sky conditions can be synthesised accurately and efficiently from only 145 computationally expensive Radiance simulations. ${ }^{18}$ Using the BREIDMP validation dataset, Mardaljevic has shown that the 4-Component CBDM simulation has a comparable high accuracy to the standard Radiance calculation used for a single point in time simulation (see note 16 above).

The lighting simulation parameters that determine the potential accuracy and precision of the predictions were tested to ensure that the result (e.g. cumulative annual illuminance) converged to a stable, reliable value. The number of reflections (known as 'ambient bounces' in Radiance) was set to 7, and other key 'ambient' parameters were set to comparably high precision values. The construction and testing of the simulation are described in more detail elsewhere, ${ }^{19}$ this paper focuses on the simulation outputs and their application to light control for Hambletonian. Fig. 5 shows the simulated annual light exposure on the Main Staircase surfaces in a false colour fish eye projection.

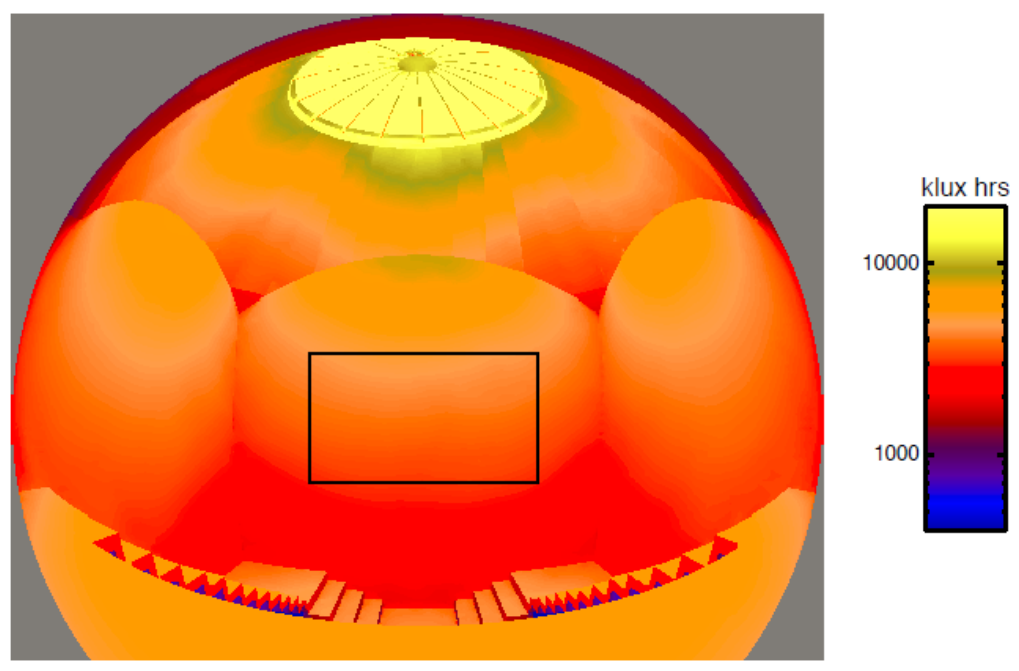

Fig. 5. Fish-eye lens projection showing simulated annual daylight exposure on surfaces in the main staircase at Mount Stewart. A false colour logarithmic scale is used to depict light exposure. The rectangle in the centre of the image shows the location of Hambletonian.

Splitting the source data by month allows a more detailed understanding of when Hambletonian receives the most exposure. Unsurprisingly this occurs during the summer months, as can be seen from the plots in Fig. 6. The annotated values on each plot are for the average across the surface of the painting. They range from approximately $50 \mathrm{klxhr}$ in December to a peak, due to the data distribution, of 
approximately $580 \mathrm{klxhr}$ in May, when effectively the painting receives the maximum recommended annual light exposure for oil paintings in a single month.
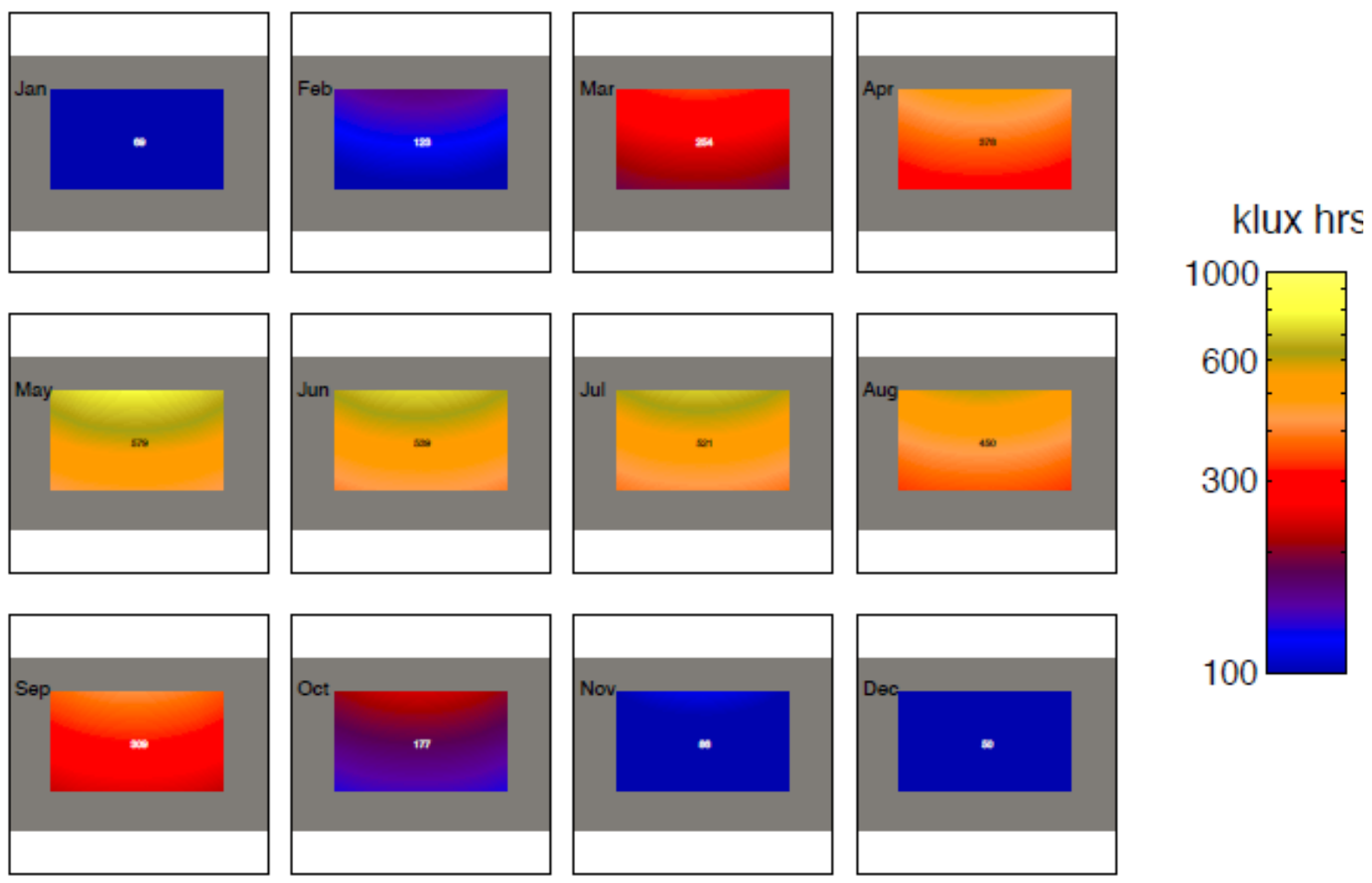

100

Fig. 6. Simulated annual daylight exposure across the surface of Hambletonian, by month of the year. A false colour logarithmic scale is used. The average monthly light exposure received by the painting surface were (in klxhr): January 69, February 123, March 254, April 378, May 579, June 539, July 521, August 450, September 309, October 177, November 86 and December 50.

The simulation of the main staircase generated an annual exposure for the top left corner of the painting of $4.4 \mathrm{mlxhr}$ and an average across the surface of the painting of $3.5 \mathrm{mlxhr}$. These simulated values are similar to the measured annual exposures in the top left reference location (above Hambletonian's frame) of $4.1 \mathrm{mlxhr}$ (2011) and $3.3 \mathrm{mlxhr}(2012-13)$.

When comparing measured and simulated data it should be kept in mind that the measured lux exposures are determined in part by the weather conditions of the particular year of measurement, whereas the simulations are based on a standardised Belfast test reference year. Standardised climate files contain unique patterns of measurements that will never repeat in precisely the same way that they appear in measured climate data. However, one would expect annual summaries for overall performance measures to be broadly similar from one year to the next since the effects of unique patterns in the data become much less significant when a full 
year is considered. Accordingly, the agreement between measured and simulated data gave confidence in the accuracy of the simulation and its application to understanding the efficacy of light control interventions for Hambletonian.

\section{Options for daylight control}

The following light control options were proposed by Stephen Cannon-Brookes and John Mardaljevic, in their first report to the Mount Stewart conservation and representation project team: ${ }^{20}$

1. Reduce wall and ceiling reflectance. by changing colour

2. Reduce overall transmittance of glazing by introducing external screening, possibly for use during summer months only.

3. Introduce partial, directional shading to reduce direct sun at key times of day and year.

4. Introduce a blackout blind with active control to exclude daylight when painting is not on display.

5. Refit the dome with electrochromic glazing. Daylight is controlled by applying a voltage across the glazing causing it to change between clear and tinted states.

6. Build an external structure over the dome to exclude daylight, which is electrically lit to give the impression of daylight.

The key criteria for the Mount Stewart project team were that any solution should be simple and reliable with low demands in terms of staff time and maintenance costs. A solution had also to be implemented in the lifetime of the project which allowed little time for experimentation or delay.

Automated mechanical blind control was ruled out because of complexity and the likelihood of failure. The previous mechanically-controlled external blinds had worked for only a short time before corrosion in the salt air at Mount Stewart had caused them to fail and stick in a partially closed position. Building an external structure above the dome which could house the active blinds and protect them from the elements was considered too interventive, changing the external appearance of 
the glazed dome unacceptably and likely to be too costly and difficult to realise in the lifetime of the Mount Stewart project.

Of the solutions proposed (6) was ruled out on curatorial grounds. The project team felt there was a need to retain the impression of changing daylight conditions for the building occupants, which could not easily be replicated with electric lighting. The structure required would also affect the external appearance of the building and be costly to build

Electrochromic glazing (5) is a new product, which is beginning to be used widely in the commercial building sector, for heat as much as light reduction. It is largely untried in historic buildings, though has been installed at the St. Johnsbury Athenaeum, in the United States. ${ }^{21}$ Studies have shown that, with an appropriate control strategy, a neutral spectrum of daylight illumination can be maintained even though the glazed panels appear blue when tinted. ${ }^{22}$ This was considered too experimental and interventive for Mount Stewart, as well as too expensive. Project Architect Richard Elphick had investigated reglazing the dome with electrochromic nano smart glass and estimated the cost to be around $£ 40,000$.

The option of a blackout blind would enable a very significant reduction in light levels by excluding daylight when it is not needed to view the paintings. However an internal blackout blind would detract from the presentation of the staircase, and any external structure would potentially be unsightly and would interrupt the natural change of daylight conditions, considered important for those working in the building. The option of introducing external shading was therefore considered the most suitable form of light control, especially on the grounds of simplicity and ease of maintenance. A removable shade to be used for the summer months was considered impractical because of roof access safety issues and therefore attention was focussed on shading that could be fixed in place all year round, and preferred over the option of directional shading, which may have had some benefits for reducing peak daylight exposure but could not be explored because of project time constraints. One of the most intriguing results from the climate-based daylight modelling was the importance of reflected light in the overall light exposure received by Hambletonian. The simulation had shown that over two thirds of the daylight falling on the painting was reflected light. It was apparent that reducing the reflectance of the surface finishes on the main staircase would reduce the light 
exposure of Hambletonian. Whilst insufficient alone, it was considered that this could provide a useful control method when used in conjunction with external shading.

Serendipitously, the Staircase was to be repainted in a darker, sea-green colour scheme as had existed in the early $20^{\text {th }}$ century, as part of the re-presentation of Mount Stewart.

1 Installation of light control insect mesh screen and evaluation of results

The Mount Stewart project team therefore decided to proceed with two interventions: (i) application of external shading above the dome and (ii) reduction of internal reflectance by using the darker paint scheme.

Project architect Richard Elphick researched materials for external shading and methods of fixing to the dome. An insect screen mesh was the prototype. This was to be cut into segments to match the shape and size of each of the 16 glazed panels in the dome, sewn together and stretched into place over the dome and secured using clips or guy ropes. Samples of the insect mesh and technical data on the new paint finishes were provided to Mardaljevic and Cannon-Brookes who completed a second set of simulations to calculate Hambletonian's annual light exposure with the proposed interventions. These results are presented in table 1.

The simulations showed that repainting with the darker paint finishes would reduce the annual light exposure from $3.5 \mathrm{mlxhr}$ to $2.5 \mathrm{mlxhr}$ and that introducing the mesh cover over the dome would further reduce the light exposure to $0.8 \mathrm{mlxhr}$. This is close to the National Trust's $0.6 \mathrm{mlxhr}$ recommended maximum annual light exposure for moderately sensitive objects and would represent a great improvement for conservation of the painting. However, as these control measures were planned to be in place all year round, there was a risk that at times daylight illumination would fall below 50 lux, the value generally considered as the lowest light level that gives satisfactory viewing of artworks. ${ }^{23}$ The simulation approach was able to help answer this question by showing that with the combined measures, the average daylight illuminance across the painting would fall below 50 lux for a quarter of daylight hours in the year. Further simulations were undertaken later in the project to understand how many of these hours would fall during times when Mount Stewart is open for visitors. Meanwhile, it was decided to proceed with prototype mesh cover, which was custom made and installed on the dome in May 2013. The new paint 
finishes were not yet applied as this work was scheduled as part of the full Mount Stewart redecoration, due to begin in 2014

The prototype mesh cover by itself proved effective at light reduction, but as first installed it did not hold its shape well and creases in the mesh were visible from below the dome (Fig. 7). The light reduction achieved by the mesh was assessed from lux data recorded by a sensor placed to the top left of Hambletonian's picture frame.

Table 1. Main Staircase, Mount Stewart. Modelled light exposures received by Hambletonian (average across painting) with different light transmittances and surface reflection properties and percentage reductions achieved by each intervention. Glazing transmittance of the diffusive frosted glazing was measured in situ by SCB. Mesh transmittance was measured on a sample of the material at Loughborough University.

\begin{tabular}{|c|c|c|c|c|c|c|c|}
\hline & $\begin{array}{l}\text { Light } \\
\text { trans- } \\
\text { mittance }\end{array}$ & Light & flectance & (\%) & & & \\
\hline Scenario & $\begin{array}{l}\text { Glazing + } \\
\text { shading }\end{array}$ & $\begin{array}{l}\text { Wall } \\
\text { finish }\end{array}$ & $\begin{array}{l}\text { Ceiling } \\
\text { finish }\end{array}$ & $\begin{array}{l}\text { Stair } \\
\text { carpet }\end{array}$ & $\begin{array}{l}\text { Stone } \\
\text { steps }\end{array}$ & $\begin{array}{l}\text { exposure } \\
\text { (mlxhr) }\end{array}$ & $\begin{array}{l}\% \text { light } \\
\text { exposure } \\
\text { reduction }\end{array}$ \\
\hline $\begin{array}{l}\text { Initial paint finishes } \\
\text { and unshaded } \\
\text { diffusive frosted } \\
\text { glazing }\end{array}$ & 59 & 60 & 80 & 25 & 55 & 3.5 & \\
\hline Prototype mesh cover & 19 & 60 & 80 & 25 & 55 & 1.7 & 49 \\
\hline $\begin{array}{l}\text { New paint finishes - } \\
\text { wall 'Reef Green' } \\
\text { Ceiling 'Joas White' }\end{array}$ & 59 & 22 & 64 & 25 & 55 & 2.5 & 29 \\
\hline $\begin{array}{l}\text { New paint finishes } \\
\text { plus prototype mesh } \\
\text { cover }\end{array}$ & 19 & 22 & 64 & 25 & 55 & 0.8 & 77 \\
\hline
\end{tabular}




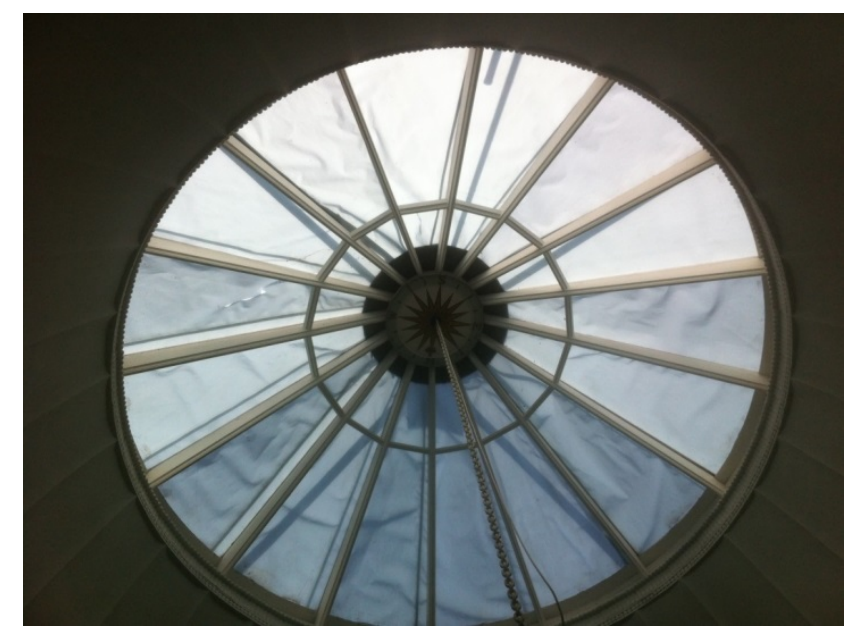

Fig. 7. View from below the staircase dome of the prototype light-reducing mesh cover, installed, May 2013. Creasing and a tear in the mesh can be clearly seen.

Hambletonian was taken down and removed to storage in December 2013, whilst the building was redecorated. It was not rehung until early 2015. During 2014 the opportunity arose to improve on the prototype mesh installation. Richard Elphick identified a marine mesh product, Phifertex® (a grey vinyl coated polyester mesh), as likely to be more resilient to the weather and UV degradation and easier to make into the precise shape and size needed to fit the glazed dome. The mesh screen was made by a marine sailmaker to the architect's specification and delivered to site and installed in early 2015. The mesh was secured in place using catches and lines developed for marine use (Fig. 8).
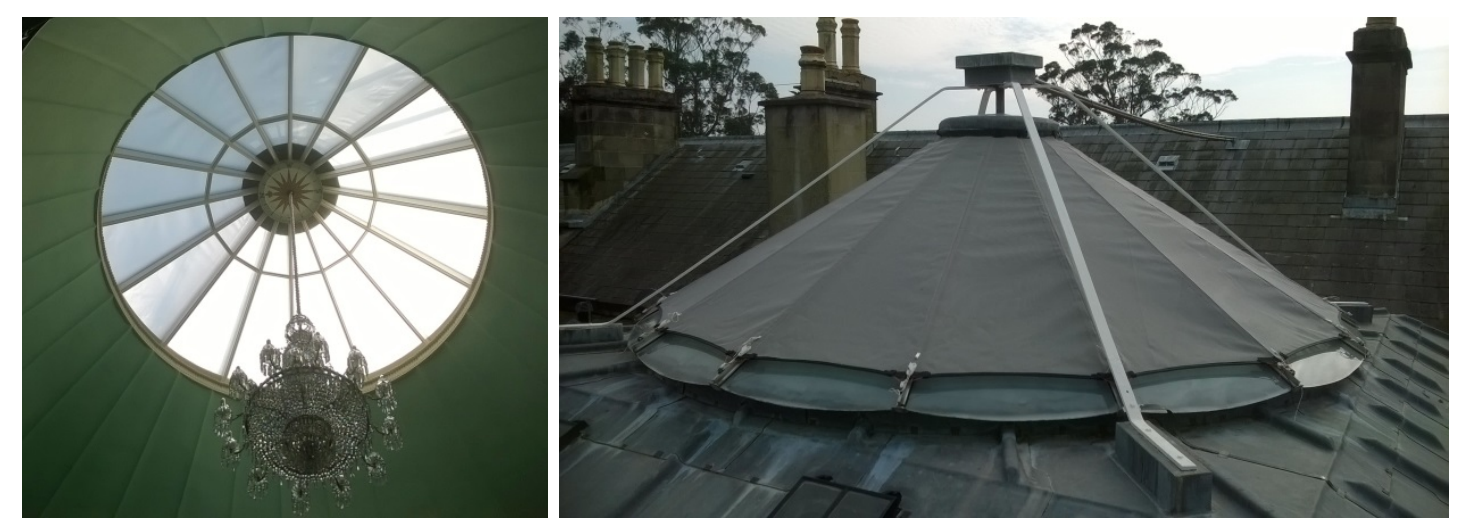

Fig. 8. View of the second light-reducing Phifertex® mesh to be installed, from below the dome (left) and as attached to the outside of the dome using marine fixings (right), March 2015.

From below, light and shade are still visible through the new mesh, which has a much more uniform appearance than the first mesh. The fixings on the outside of 
the dome have proved secure against the weather and the mesh is washed by the rain. In terms of maintenance, only occasional cleaning of leaves trapped between the glazing and mesh has proved necessary in the first year of operation. The total cost for manufacture and installation of the mesh was $£ 2500$, with an expected service life of at least five to ten years.

Further research on the original Staircase paint scheme led to a small change to the wall colour and a significant shift in the ceiling colour from Joas white to sea-green.

Samples of the new mesh and new paint swatches were provided for transmittance and reflectance measurement at Loughborough University so that they could be rerun in the daylight model. The reflectance of the paint samples was determined from paired measurements of luminance and illuminance using calibrated meters, KonicaMinolta and Hagner respectively. The transmittance of the mesh samples was determined from the mean of illuminance measurements taken using directional light from different angles. The results of the second set of simulations are summarised in table 2. With the new paint finishes and mesh the annual light exposure across Hambletonian is calculated to be $0.63 \mathrm{mlxhr}$, approximately the maximum recommended National Trust light exposure of $0.6 \mathrm{mlxhr}$.

Table 2. Main Staircase, Mount Stewart. Modelled light exposures received by Hambletonian (average across painting) with revised paint finishes and new Phifertex $₫$ mesh, and percentage reductions achieved by each intervention. The new mesh had a lower light transmittance of $25 \%$, compared with $32 \%$ for the previous mesh.

\begin{tabular}{|c|c|c|c|c|c|c|c|}
\hline & $\begin{array}{l}\text { Light trans- } \\
\text { mittance (\%) }\end{array}$ & Light & eflectan & e (\%) & & & \\
\hline Scenario & $\begin{array}{l}\text { Glazing + } \\
\text { shading }\end{array}$ & $\begin{array}{l}\text { Wall } \\
\text { finish }\end{array}$ & $\begin{array}{l}\text { Ceiling } \\
\text { finish }\end{array}$ & $\begin{array}{l}\text { Stair } \\
\text { carpet }\end{array}$ & $\begin{array}{l}\text { Stone } \\
\text { steps }\end{array}$ & $\begin{array}{l}\text { Annual } \\
\text { light } \\
\text { exposure } \\
\text { (mlxhrs) }\end{array}$ & $\begin{array}{l}\% \text { light } \\
\text { exposure } \\
\text { reduction }\end{array}$ \\
\hline $\begin{array}{l}\text { Initial paint finishes } \\
\text { and unshaded glazing }\end{array}$ & 59 & 60 & 80 & 25 & 55 & 3.5 & \\
\hline $\begin{array}{l}\text { Revised paint finishes } \\
\text { - wall 'Sea Green' } \\
\text { Ceiling 'Light Green' }\end{array}$ & 59 & 40 & 49 & 25 & 55 & 2.6 & 26 \\
\hline New Phifertex® mesh & 15 & 60 & 80 & 25 & 55 & 1.6 & 54 \\
\hline $\begin{array}{l}\text { Revised paint finishes } \\
\text { and mesh combined }\end{array}$ & 15 & 40 & 49 & 25 & 55 & 0.63 & 82 \\
\hline
\end{tabular}


2 Assessing mesh performance from measured lux data

Illuminance levels on Hambletonian have been recorded electronically since 2006. The calculation of annual light exposures from partial-year measured data has been described above. Ideally a year's control monitoring data would have been collected, followed by a year of data for each of the interventions, all with the sensor in the same location. However due to the short timescale and practicalities of the conservation and re-representation project, this was not possible. The redecoration of the Staircase required Hambletonian to be moved into storage in December 2013, so that a full year's data with the first mesh on the dome could not be collected. Therefore the data were normalised to an annual light exposure using the method described earlier.

A full annual data set had been collected for the second mesh and paint finishes, but on redecoration the sensor was relocated for practical reasons to a position at the lower left of Hambletonian (Fig. 9). The simulations had shown that this lower left location receives much less light than the top of the frame. In order to estimate the light exposure at the top of the frame location from the lower left dataset, in March 2016, reference sensors were placed in both locations to record lux simultaneously for several weeks. It was assumed that there would be a simple linear relationship between illuminance at the two locations, provided the locations were both only illuminated by diffuse light. The earlier investigations of the glazing and CBDM both provided evidence that this assumption was correct. Regression analysis of the reference measurements determined that the illuminance at the top of the frame was, on average, 2.6 times the lower left illuminance. This factor was used to estimate the annual light exposure at the top left reference location for the second mesh and final paint finishes. These data transformations and the final calculated annual luxhour exposures are summarised in table 3 . The light control benefits of the meshes and changes in paint finish are evident, with the most recent year, 201516 recording a total light exposure of just below $1.0 \mathrm{mlxhr}$. The difference between the two control year datasets (2011, $4.1 \mathrm{mlxhr}$ and 2012-13, $3.3 \mathrm{mlxhr}$ (respectively) is noteworthy. This shows a higher than expected inter-year variability. Further investigations of weather station data are under way to check this result and will be the subject of a future publication. 

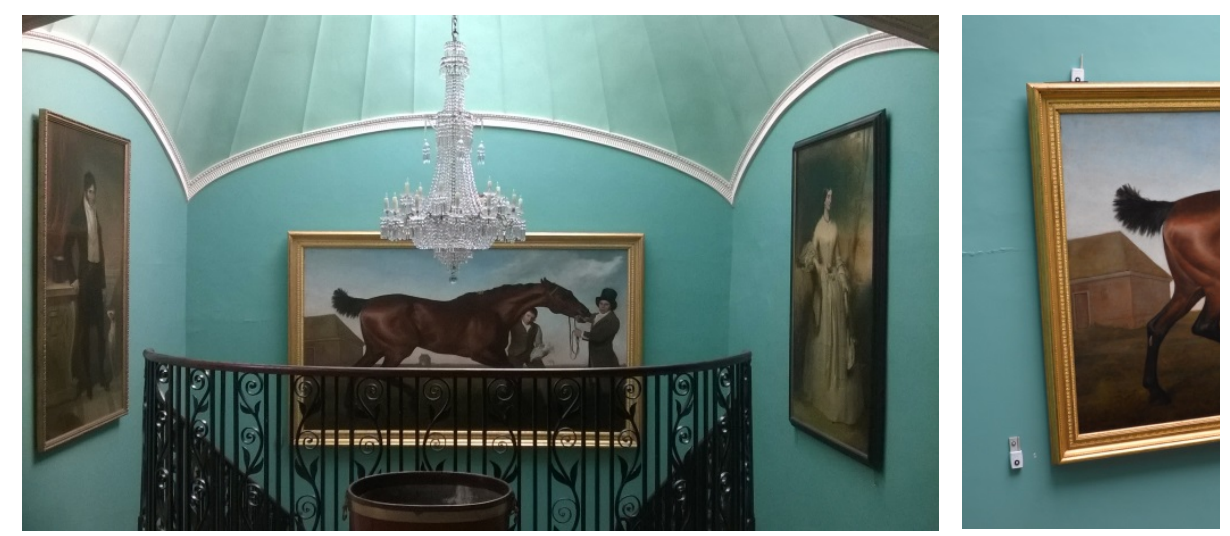

Fig. 9. Left: Hambletonian as redisplayed in March 2015, with new frame and paint finishes and Phifertex ${ }^{\circledR}$ mesh in place over the skylight. Right: the two reference sensors in (1) the old top of frame and (2) new lower left monitoring locations, June 2016.

Table 3. Annualised measured datasets before and after light control interventions.

\begin{tabular}{|c|c|c|c|c|c|}
\hline Interventions & Date from & Date to & $\begin{array}{l}\text { Fraction of } \\
\text { annual } \\
\text { light } \\
\text { exposure }\end{array}$ & $\begin{array}{l}\text { Recorded } \\
\text { lux hours }\end{array}$ & $\begin{array}{l}\text { Annualised lux hours for } \\
\text { top of frame sensor locati } \\
\text { (mlxhr) }\end{array}$ \\
\hline $\begin{array}{l}\text { No interventions - control } \\
\text { data set } 1\end{array}$ & $17 / 01 / 2011$ & $31 / 07 / 2011$ & 0.697 & $2,882,049$ & 4.1 \\
\hline $\begin{array}{l}\text { No interventions - control } \\
\text { data set } 2\end{array}$ & $16 / 08 / 2012$ & $23 / 05 / 2013$ & 0.5827 & $1,933,027$ & 3.3 \\
\hline $\begin{array}{l}\text { Average exposure for } 2011 \\
\text { and } 2012-13 \text { (no } \\
\text { interventions) }\end{array}$ & & & & & 3.7 \\
\hline \multirow[t]{2}{*}{$\begin{array}{l}\text { Prototype mesh over } \\
\text { glazed dome }\end{array}$} & $23 / 05 / 2013$ & $18 / 12 / 2013$ & 0.634 & 684,411 & 1.1 \\
\hline & & & $\begin{array}{l}\text { Scaling } \\
\text { factor for } \\
\text { sensor } \\
\text { location }\end{array}$ & $\begin{array}{l}\text { Recorded } \\
\text { lux hours } \\
\text { lower left }\end{array}$ & \\
\hline $\begin{array}{l}\text { Phifertex® mesh over } \\
\text { glazed dome, sea-green } \\
\text { paint finish to walls, lighter } \\
\text { green applied to ceiling }\end{array}$ & 01/04/2015 & $30 / 03 / 2016$ & 2.6 & 385,990 & 1.0 \\
\hline
\end{tabular}

\section{Comparing measured and simulated light exposure data}

Throughout this research the measured and simulated data complemented each other: the measured data provided a benchmark for checking the simulation outputs, 
whilst simulation results such as the relative light exposure contribution of different months of the year have helped us to identify anomalies in the measured data.

The simulation results were available at the design stage for each of the interventions and enabled a prediction of resulting light exposure before installation, so that we could understand the light control benefits that would result.

There is reasonable agreement between the measured and modelled percentage reductions in light exposure for the Phifertex® mesh and paint finish interventions, where the measured light reduction was $9 \%$ less than predicted by CBDM (table 4). For the prototype mesh, the measured light reduction exceeded the predicted reduction by $20 \%$. Sources of error include the model itself, particularly in terms of the rendering of the physical geometry and detailing of the main staircase and dome, which of necessity must be simplified: not every physical feature or its effect on daylight transmission or reflectance can be included, such as reflection from the frame top, which may have contributed to additional light being recorded by the lux sensor positioned there. Before the Mount Stewart conservation and re-presentation project, Hambletonian had been mounted in a frame flush-fitted to the wall and painted the same colour as the wall (Fig. 2). After the redecoration in 2014, Hambletonian was mounted in a traditional gilt frame (Fig. 9) as this was considered more in keeping with the new decorative scheme. The old and new frames will have different reflectance characteristics which are not represented in the simulation, which was made for the canvas surface of the painting and does not include calculations for shading or reflection due to the different frames. Furthermore, the prototype mesh may have been more prone to the accumulation of dirt, thereby reducing its light transmission, as it was not so tautly strung as the second mesh. This latter mesh, in contrast, was observed to be in a clean state one year after installation. We have found the agreement between simulated and measured data sufficiently close for the measured data and model outputs to be used in a complementary manner to improve the light control of Hambletonian. It is clear that the light reduction from the cost-effective and low-maintenance installation of the mesh and change in paint finishes has been successful and the light exposure received by Hambletonian now approaches the National Trust recommendation of $0.6 \mathrm{mlxhr}$ per year, with simulation suggesting that the painting will receive 0.63 mlxhr per year across its surface, and the measured data at the top of frame reference point showing $1.0 \mathrm{mlxhr}$ in the first year of operation. 
Table 4. Comparisons of percentage reduction in light exposure for modelled (tables 1 and 2) and measured (table 3 ) data, from base case with no mesh and original paint finishes to prototype mesh installed and replacement Phifertex® mesh. The average of 2011 and 2012-13 annualised luxhours are taken as the measured base case value.

\begin{tabular}{lll}
\hline & $\begin{array}{l}\text { Modelled reduction in annual } \\
\text { light exposure across } \\
\text { Hambletonian }\end{array}$ & $\begin{array}{l}\text { Measured reduction in annual light } \\
\text { exposure at top left of frame } \\
\text { reference point }\end{array}$ \\
\hline Prototype mesh (2013) & $51 \%$ & $71 \%$ \\
$\begin{array}{l}\text { Phifertex® mesh + new } \\
\text { paint finishes }(2015-)\end{array}$ & $82 \%$ & $73 \%$ \\
\hline
\end{tabular}

The risk of differential fading resulting from 'uneven' illumination arising from daylight was considered. The simulation demonstrates the evenness of the diffusive top lighting, with the variation in total annual illuminance across the horizontal top third of the painting with the sky colour being no more than $8 \%$. By contrast, the vertical gradient of illuminance is far more pronounced, with total annual illuminance decreasing by $39 \%$ from the centre top location to centre bottom location. Given the horizontal thrust of the composition, it can be argued that any differential fading is unlikely to be evident to the viewer.

Whilst the lower light level is undoubtedly a benefit for conservation, there was concern as to whether the light control had reduced the winter light levels below the 50 lux required for satisfactory viewing. There was no evidence of this from visitors' or other building occupants' responses during the first year of opening: visitors' comment cards were universally positive about the re-display of Hambletonian.

The climate-based daylight model was used to predict the level of daylight illumination for visitors through the year, with Hambletonian's illuminance for winter and summer opening times, dividing the data into hours above and below 50 lux (Table 5). In summer $12 \%$ of the opening hours were below 50 lux, rising to $29 \%$ of the opening hours in winter. For these hours the average illuminance at the centre of the painting was 34 lux. From the comment cards received through the winter, it appears that visitors have found this level of illumination acceptable. It may be that by the time visitors reach Hambletonian they have adapted to the lower winter light levels in the house, where most rooms are side-lit from the windows with supplementary electric lighting. In contrast, the skylighting above the staircase appears relatively bright. Awareness of the transition from light to dark areas is an 
important aspect of designing visitor routes that avoid dazzling visitors or plunging them into a stygian gloom, and thus detracting from their experience and enjoyment of historic house interiors.

Table 5. Times of low illuminance ( $<50$ lux) of centre of Hambletonian during summer opening (seven days per week, $14 \mathrm{Mar}-30$ Oct, 11.00-17.00) and winter opening (Saturdays and Sundays only, 1 Nov - 13 Mar, 11.00-15.00). Simulated data for Hambletonian as displayed from 2015 with Phifertex® mesh and sea green/light green paint finishes. The average illuminance for summer hours $<50$ lux is less than in winter because it includes hours of dusk in March and October.

\begin{tabular}{lllll}
\hline $\mathbf{I}$ & $\begin{array}{l}\text { Percentage of } \\
\text { opening hours } \\
\text { with illuminance } \\
\mathbf{5 0} \text { lux }\end{array}$ & $\begin{array}{l}\text { Average } \\
\text { illuminance for } \\
\text { those hours } \\
\text { (lux) }\end{array}$ & $\begin{array}{l}\text { Percentage of } \\
\text { opening hours } \\
\text { with illuminance } \\
\mathbf{5 0 ~ l u x}\end{array}$ & $\begin{array}{l}\text { Average } \\
\text { illuminance for } \\
\text { those hours (lux) }\end{array}$ \\
\hline Summer & $88 \%$ & 229 & $12 \%$ & 23 \\
Winter & $71 \%$ & 114 & $29 \%$ & 34 \\
\hline
\end{tabular}

\section{Conclusions}

The application of climate-based daylight modelling in the project to improve light control of the top lit staircase at Mount Stewart enabled several beneficial outcomes:

1. Daylight characteristics of the main staircase are better understood. Direct sunlight is prevented from reaching any of the paintings because of the diffusing effect of the extant frosted glass. Furthermore, the simulation showed that, with clear glazing, direct sunlight would fall on the paintings on the adjacent walls but not Hambletonian itself.

2. CBDM has made evident the effect of different decorative schemes on reflected light. This demonstrates the potential for manipulating paint colours to enhance light management for conservation purposes so long as curatorial and presentation objectives are attained.

3. CBDM gave confidence to the decision to use a mesh cover by modelling how well it might work before any installation was begun.

4. Whilst a measurement sensor can record light exposure at a single reference point, close to, but not directly on an object, CBDM can give information on the spatial distribution of the light received across that object. Thus CBDM 
may more accurately represent the light exposure of the object itself rather than from measured data collected from an always slightly adjacent point.

5. Light data collected as part of routine monitoring required a significant research effort to produce robust datasets which accurately characterised the exposure conditions of Hambletonian with and without the mesh covers.

6. Further research is underway using high dynamic range (HDR) image capture at other National Trust properties. This has the potential to map the spatial distribution of light exposure in a historic building, producing an output similar to CBDM, but based on actual measurement rather than simulation.

7. Measurement and simulation both show the interventions have reduced light exposure to a level close to the upper acceptable limit for moderately light sensitive objects. In effect the mesh is acting as a neutral density filter, but as it is not adhered to the glass, it can be adjusted or easily replaced in the future.

8. The mesh cover has proved visually acceptable to both visitors and occupants, as evidenced through visitors comment cards and on usergenerated content websites such as Trip Advisor.

9. The mesh cover has proved robust, cost-effective and low maintenance a year after installation, whilst allowing for later modification. The success of the mesh cover has led to two more covers being designed and constructed for other roof lanterns in Mount Stewart's Staircase Hall.

However, some issues remain to be resolved in terms of implementing appropriate light control measures:

1. The presence of photo-sensitive pigments such as Prussian blue, orpiment and the remains of organic red lakes could be interpreted as suggesting that the annual light exposure should be reduced further to $0.15 \mathrm{mlxhr}$, or a steady illuminance maintained of 50 lux. In relation to this, and as part of the monitoring of the work, a programme of quinquennial colour measurement of Hambletonian's sky pigments has been instigated and will be reported in the future. Depending on results, further modulation of the light by including the application of a second layer of mesh during the summer months (JuneAugust) might be appropriate although safety issues with regard to roof 
access make this potentially too hazardous. In the longer term, and once its suitability is established, reglazing the roof lantern with electrochromic glass may also be an option.

2. Diffusive frosted glazing can increase exposure for objects not in direct sunlight, even if they are protected from direct illumination. On the positive side, this may help viewers in providing more even illumination, which cannot be achieved by a neutral density filter on its own.

In conclusion, this study has shown how techniques developed in building science research can be used to help solve practical conservation problems. In turn, this heritage project has enabled such researchers to develop their methodology and to use and analyse measured data alongside the simulation. Furthermore, the promising outcomes garnered in using climate based daylight modelling for top lighting have led to a study on side lit rooms, which the authors will report on in due course.

\section{Endnotes}

1 Signed and dated 1800 and exhibited at the Royal Academy 1800. See Judy Egerton, George Stubbs, Painter. Catalogue Raisonné (London: Yale University Press/Paul Mellon Centre, 2007), 98, 624-5.

2 The painting shows the horse exhausted, but without the wounds of whip and spur inflicted during the race. Sir Henry refused to pay the 300 guineas agreed for it until Stubbs went to court. Consequently the companion painting of the race being won originally commissioned by Sir Henry from Stubbs was not painted by Stubbs but by James Ward some decades later, based on a sketch by Stubbs in a more conventional style that now hangs at Mount Stewart in the Dining Room. A contemporary account from the Sporting Magazine is detailed in Egerton, George Stubbs, Painter, 624.

3 The house continued to be improved during the nineteenth century, including the creation of the black and white stone hall into which the staircase flows, part of the 
William Vitruvius Morrison extension of the late 1840 s commissioned by Charles, $3^{\text {rd }}$ Marquess.

4 Frances Bailey, Mount Stewart: Stubbs meets Dance: outline history of the installation of shuttering above the Dance dome to protect Stubbs' Hambletonian from light damage (National Trust unpublished report, 2005).

5 As described by Christine Sitwell in personal communication with the authors; also see 'Catalogue No 138 Hambletonian, Rubbing Down', in George Stubbs, 1724-1806, ed. Judy Egerton (London: Tate Publishing, 1984), 181-2.

6 See Robert Shepherd, 'Stubbs: A Conservator's View', in Egerton, ed., George Stubbs, 1724-1806, 20-1; and Ian McClure and Rupert Featherstone, 'The Cleaning of Stubb's “Hambletonian” (No. 138)', in Egerton, ed., George Stubbs, 1724-1806, 22-3.

7 Lance Mayer and Gay Myers, 'Painting in an Age of Innovation: Stubbs's Experiments in Enamel and Wax', in Stubbs and the Horse, ed. Malcolm Warner and Robin Blake (New Haven and London: Yale University Press, 2004), 123-140.

8 See, for example, Jo Kirby, 'Fading and Colour Change of Prussian Blue: Occurrences and Early Reports', National Gallery Technical Bulletin 14 (1993): 6271; Barbara H. Berrie, 'Prussian Blue', in Artist's Pigments. A Handbook of Their History and Characteristics. Volume 3, ed. Elizabeth West Fitzhugh (Oxford: Oxford University Press, 1997), 191-217; Claire Gervais, Marie-Angelique Languille, Solenn Reguer, Chantal Garnier and Martine Gillet, 'Light and Anoxia Fading of Prussian Blue Dyed Textiles', Heritage Science 2 (2014): 26; and Anna Vila, Kasper Monrad, Troels Filtenborg and Jørgen Wadum, 'As Time Passed by Came Sunset. Christen Købke's View of Lake Sortedam, its Genesis and Colour Changes', in Science and Art: The Painted Surface, ed. Antonio Sagamellottie, Brunetto Giovanni Brunetti and Costanza Miliani (London: Royal Society of Chemistry, 2014), 354-72. 
9 See West Fitzhugh, ed., Artist's Pigments; and Katrien Keune, Jennifer Mass, Apurva Mehta, Jonathan Church and Florian Meirer, 'Analytical Imaging Studies of the Migration of Degraded Orpiment, Realgar, and Emerald Green Pigments in Historic Paintings and Related Conservation Issues', Heritage Science 4 (2016): 2.

10 cf. Robert Lewis, 'The Display Implications of the Presence of Orpiment on a Child's Coffin', in The Object in Context: Crossing Conservation Boundaries: Contributions to the Munich Congress 28 August-1 September 2006, ed. David Saunders, Joyce Townsend and Sally Woodcock (London: International Institute for Conservation, 2006), 341.

11 A policy informed in part by Garry Thomson's, The Museum Environment (Conservation and Museology), 2nd edn (London: Butterworth-Heinemann, 1986). See National Trust, The National Trust Manual of Housekeeping: Care and Conservation of Collections in Historic Houses Open to the Public (London: National Trust, 2011), 96.

12 cf. Charted Institute of Building Service Engineers/Society of Light and Lighting, Lighting Guide 11: Surface Reflectance and Colour (London: Chartered Institution of Building Services Engineers, 2001). Measurements and calibration of the sample cards were carried out by the National Physical Laboratory.

13 John Mardaljevic, Ruth Kelly Waskett, and Birgit Painter, 'Neutral Daylight Illumination with Variable Transmission Glass: Theory and Validation', Lighting Research and Technology 48, no. 3 (2016): 267-85.

14 John Mardaljevic, 'Verification of Program Accuracy for Illuminance Modelling: Assumptions, Methodology and an Examination of Conflicting Findings', Lighting Research and Technology 36, no. 3 (2004): 217-39.

15 See Greg Ward Larson, Rob A. Shakespeare, John Mardaljevic, Charles Ehrlich, Erich Phillips and Peter Apian-Bennewitz, Rendering with Radiance: The Art and Science of Lighting Visualization (San Francisco: Morgan Kaufmann, 1998). See 
also, Gregory J. Ward, 'The RADIANCE Lighting Simulation and Rendering', in Proceedings from SIGGRAPH '94: The $21^{\text {st }}$ Annual Conference on Computer Graphics and Interactive Techniques (New York: ACM, 1994), 459-72, http://radsite.lbl.gov/radiance/papers/sg94.1/Siggraph1994a.pdf (accessed 7 July 2016).

16 See, for example, John Mardaljevic, 'Validation of a Lighting Simulation Program under Real Sky Conditions', Lighting Research and Technology 27, no. 4 (1995): 181-8; John Mardaljevic, 'The BRE-IDMP Dataset: A New Benchmark for the Validation of Illuminance Prediction Techniques', Lighting Research and Technology 33, no. 2 (2001): 117-34.

17 See, for example, Stephen Cannon-Brookes, 'Simple Scale Models for Daylighting Design: Analysis of Sources of Error in Illuminance Prediction', Lighting Research and Technology 29, no. 3 (1997): 135-42.

18 For a description of the daylight coefficient approach, see Peter R. Tregenza and Isobel M. Waters, 'Daylight Coefficients', Lighting Research and Technology 15, no. 2 (1983): 65-71, 1. The 4-Component method is described in: John Mardaljevic, 'Daylight Simulation: Validation, Sky Models and Daylight Coefficients' (PhD thesis, De Montfort University, Leicester, 2000).

19 John Mardaljevic, Stephen Cannon-Brookes, Katy Lithgow and Nigel Blades, 'Illumination and Conservation: A Case Study Evaluation of Daylight Exposure for an Artwork Displayed in an Historic Building', Presentation to the 28th Session of the International Commission on Illumination (CIE 2015), $28^{\text {th }}$ June-4th July 2015, Manchester (Commission Internationale de l'Eclairage, 2015), https://dspace.lboro.ac.uk/2134/19991

20 Stephen Cannon-Brookes and John Mardaljevic, 'Analysis of Daylighting Conditions on Hambletonian and the Stone Staircase, Mount Stewart. Report and Recommendations 28th May 2012' (unpublished report for the National Trust, 2012). 
21 St Johnsbury Athenaeum, A Touch of Glass: Restoration of the Historic Gallery Skylights (St Johnsbury Athenaeum),

http://www.stjathenaeum.org/skylightproject.htm (accessed 7 July 2016).

22 See, for example, Mardaljevic, Waskett and Painter, 'Neutral Daylight Illumination with Variable Transmission Glass', 267-85.

23 See, for example, David Loe, Edward Rowlands and Newton Watson, 'Preferred Lighting Conditions for the Display of Oil and Watercolour Paintings', Lighting Research and Technology 14, no. 4 (1982): 173-92; Christopher Cuttle, Light for Art's Sake, Lighting for Artworks and Museum Displays (Oxford: ButterworthHeinemann, 2007).

\section{Acknowledgements}

We would like to thank Frances Bailey, Claire Magill and Louise Newstead of the Mount Stewart National Trust project team for their assistance throughout the research, and Lisa McCullough (National Trust) for help with on-site monitoring. We are grateful to Richard Elphick of Elphick Associates, Consultant Conservation Architect, and project architect for Mount Stewart, who provided information on electrochromic glazing and the mesh covers, which were constructed to his design. We would also like to thank John Meneely for making available to us 3-D laser scanning data for the Main Stairs at Mount Stewart. 


\section{Materials, suppliers}

Insect Mesh:

$1.9 \mathrm{~mm}$ hole $1.5 \times 50 \mathrm{~m}$ long

Hanscan Ltd

Unit 85 Fraylings Business Park

Daventport St

Burshlem

Stoke on Trent ST6 4LN

UK

amin@meshdirect.co.uk

Bespoke manufacturing by:

Keith of Tedfords Ltd

Sailmakers

Unit 24 Ormeau Business Park

8 Cromac Avenue

Belfast BT7 2JA

UK

http://www.tedfords.co.uk/.

Phifertex® vinyl coated polyester mesh (grey):

Kayospruce Ltd

2 Cockerell Close

Segensworth West

Fareham Hampshire

P015 5SR

UK

http://www.kayospruce.com/

Mesh cover manufactured by:

Storrar Marine Store

181-183 Coast Road

Newcastle upon Tyne NE7 7RR 
UK

http://www.storrarmarine.co.uk/

Hanwell ML4703 combined lux and UV radiotelemetric sensor:

IMC Group

Pendle House

Jubilee Road

Letchworth

Hertfordshire SG6 1SP

UK

http://www.the-imcgroup.com/

Blue wool supplied by:

SDC Enterprises Limited

Unit 29 Pitcliffe Way

Upper Castle Street

Bradford BD5 7SG

UK

http://www.sdcenterprises.co.uk/

Reflectance Cards Lighting Guide 11 Chart:

Reflectance Sample Chart (LG11RSC)

Chartered Institute of Building Service Engineers

222 Balham High Road

London

SW12 9BS

UK

http://www.cibse.org/Knowledge/CIBSELG/Lighting-Guide-11-Chart-ReflectanceSample-Chart 


\section{Biographies}

Nigel Blades is Preventive Conservation Adviser (Environment) for the National Trust. His main role is to advise on environmental control solutions and preventive conservation for the care of collections; and oversee environmental data collection and interpretation for the Trust's historic properties. Dr Blades provides training and technical support in preventive conservation for house staff through property advisory visits and training courses and is closely involved with the Trust's conservation science research. Before joining the National Trust in $2008 \mathrm{Dr}$ Blades was Lecturer at the UCL Centre for Sustainable Heritage, where he was joint course director for the MSc Sustainable Heritage and undertook research into preventive conservation.

Address: National Trust, 20 Grosvenor Gardens, London SW1W 0DH, UK. Email: nigel.blades@nationaltrust.org.uk.

Katy Lithgow has a BA Hons in Archaeology, Anthropology and History of Art from Cambridge, and the Postgraduate Diploma in Wall Paintings Conservation from the Courtauld Institute of Art, London, where she taught following an internship at the Victoria and Albert Museum, London. She joined the National Trust in 1991 as a preventive conservator, specializing in storage and protecting collections during building works. In 1995 she became the Trust's Wall Painting Conservation Adviser and in 2002 Conservation Advisers Manager, before being appointed Head Conservator in 2005. She has published and lectured on wall painting conservation, preventive conservation, conservation management, interpretation in conservation, heritage science and sustainability. Katy is an Accredited Conservator-Restorer (ACR), Chair of the PACR scheme's Accreditation Committee, and a Trustee of the National Heritage Science Forum.

Address: National Trust, Heelis, Kemble Drive, Swindon SN2 2NA, UK. Email: katy.lithgow@nationaltrust.org.uk. 
Stephen Cannon-Brookes (PhD, FSLL) is principal of $\mathrm{CBL}$, a specialist lighting consultancy. His work is focused on lighting for museums and historic buildings as well as privately owned collections. He holds a part-time lectureship at the Bartlett School of Architecture, UCL and has taught on the Exhibition Design MSc at the Technical University in Graz, Austria and in St Petersburg. He has been President of the International Council of Museums' Architecture Committee, Chair of the Daylight Group of the Chartered Institute of Building Services Engineers as well as President of the UK's Society of Light and Lighting.

Address: Cannon-Brookes Lighting \& Design, 10 Brooksville Avenue, London NW6 6TG, UK. Email: stephen@cblighting.com.

John Mardaljevic (PhD, FSLL) is Professor of Building Daylight Modelling at the School of Civil \& Building Engineering, Loughborough University. Mardaljevic pioneered what is now known as Climate-Based Daylight Modelling. Mardaljevic's practice-based research and consultancy includes major projects such as the New York Times Building and The Hermitage (St. Petersburg). He currently serves as the 'UK Principal Expert on Daylight' for the European Committee for Standardisation CEN / TC 169 WG11 and is CIE-UK Representative for Division 3 (Interior Environment). In 2012 Mardaljevic was presented the annual UK lighting award by the Society for Light and Lighting (SLL).

Address: School of Civil \& Building Engineering, Loughborough University, Loughborough, Leicestershire, LE11 3TU, UK. Email: J.Mardaljevic@lboro.ac.uk. 